https://artnodes.uoc.edu

\title{
Entre lo vivo y lo no vivo. Edadismo, capacitismo, LGTBIQ*fobia y artivismo antirracista en el Estado español durante los primeros meses de la COVID-19
}

\author{
Andrés Senra \\ Universitat Oberta de Catalunya \\ Fecha de presentación: septiembre de 2020 \\ Fecha de aceptación: diciembre de 2020 \\ Fecha de publicación: enero de 2021
}

\section{Cita recomendada}

Senra, Andrés. 2021. «Entre lo vivo y lo no vivo. Edadismo, capacitismo, LGTBIQ*fobia y artivismo antirracista en el Estado español durante los primeros meses de la COVID-19». En: Benítez, Laura; Berger, Erich (coord.). «Artes en tiempos de pandemia». Artnodes, num. 27: 1-10. UOC. [Consulta: dd/mm/aa]. http://doi.org/10.7238/a.v0i27.373912 SOMERIGHISRESERVED
Los textos publicados en esta revista están sujetos -si no se indica lo contrario- a una licencia de Reconocimiento 4.0 Internacional de CreativeCommons. La licencia completa se puede consultar en https://creativecommons.org/licenses/by/4.0/deed.es_ES.

\section{Resumen}

La COVID-19 representa uno de los casos más recientes donde confluyen dinámicas de racismo, crisis económica global, edadismo, capacitismo y LGTBIQ*fobia, con graves consecuencias en las relaciones sociales y personales que nos permiten repensar la pandemia como agenciamiento que refuerza las desigualdades estructurales ya existentes en el sistema de economía de mercado, además de examinar cómo responden y han respondido las comunidades afectadas. En este artículo, parto de la línea difusa entre lo vivo y lo no vivo, las representaciones mediáticas de la pandemia, los «muertos vivientes», el contagio, las metáforas de la enfermedad y el artivismo antirracista por parte de las nuevas generaciones de descendientes asiáticos en España, para analizar las dimensiones estéticas y políticas de un ensamblaje con la complejidad estructural de la COVID-19, en la que intervienen agentes humanos y no humanos. 


\title{
artnodes
}

https://artnodes.uoc.edu

Entre lo vivo y lo no vivo. Edadismo, capacitismo, LGTBIQ*fobia y artivismo antirracista en el Estado español durante los primeros meses de la COVID-19

La importancia del rol activo desempeñado por estos agentes no humanos y los considerados como no vivos en los sistemas complejos de ensamblaje social no implica perder de vista el rol decisivo que las instituciones y las personas tienen en la gestión de las políticas sanitarias y las consecuencias de estas.

\section{Palabras clave}

Vivo/no vivo, artivismo, representación, interseccionalidad, ensamblaje social, agenciamiento vírico

\section{Between the living and the non-living. Ageism, ableism, LGBTQI*phobia and anti-racist artivism in the Spanish State during the first months of COVID-19}

\begin{abstract}
COVID-19 represents one of the most recent cases where there is a convergence in dynamics of racism, a global economic crisis, ageism, ableism and LGBTQI*phobia, with serious consequences in social and personal relations which allows us to reconsider the pandemic as an assemblage that reinforces the structural inequalities already existing in the market economy system, and to examine how the communities affected are responding and have responded.

In this article I set out from the line drawn between the living and the non-living, the media representations of the pandemic, the "living dead", infection, the metaphors of the illness and the anti-racist artivism by the new generations of those of Asian descent in Spain in order to analyse the aesthetic and political dimensions of an assemblage with the structural complexity of COVID-19 in which human and non-human agents intervene.

The importance of the active role carried out by these non-human agents and those agents considered as non-living in the complex systems of social assemblage does not involve losing sight of the decisive role that institutions and people have in the management of the health policies and their consequences.
\end{abstract}

\section{Keywords}

Living/non-living, artivism, representation, intersectionality, social assemblage, viral agency

\section{Introducción}

En este texto propongo una reflexión sobre cómo la acción del virus SARSCoV-2 contribuyó a una reconfiguración de los mapas sociales (Latour, 2008) durante las primeras semanas de la pandemia de la COVID-19. Comenzaré cuestionando uno de los dualismos centrales en nuestra comprensión de la materia: la idea de vivo en oposición a la de no vivo. Esto nos ayudará a comprender cómo el rol inerte y pasivo asignado de manera tradicional a los agentes considerados como no vivos dificulta la percepción del papel fundamental y activo de organismos como los virus en los complejos procesos sociales, políticos y económicos. En el siguiente apartado, siguiendo esta lógica, analizaré la forma en la que el mercado se comporta como un ser vivo; veremos, además, cómo se relaciona con otros aspectos culturales que reflejan la percepción del virus como amenaza en la producción audiovisual en los media y cuál es el rol de todos estos elementos en el refuerzo de las desigualdades estructurales y la exclusión social presentes en la sociedad, tales como el racismo, edadismo y capacitismo. A partir de estos elementos, estudiaré algunos ejemplos de artivismo en el ámbito español en respuesta al creciente aumento del racismo contra la comunidad de origen asiático.
Esto nos permitirá concluir con las consecuencias más específicas que la pandemia ha tenido para la comunidad LGTBIQ*.

\section{Entre lo vivo y lo no vivo}

Los virus (del lat. virus 'veneno', 'ponzoña') han sido considerados de manera tradicional como un caso que desafía nuestra idea de la vida. Bien como seres vivos primarios o simplemente como estructuras formadas por moléculas orgánicas, los virus serían unos entes que se mueven en esa zona difusa entre lo vivo y lo no vivo debido a sus características específicas: no pueden replicarse por sí mismos, necesitando el aparato molecular y metabólico de las células que infectan para reproducirse.

Grosso modo, los virus son moléculas de ADN o ARN protegidas por una cápsula proteica que pierden al penetrar en la célula infectada, integrando su información genética en el ADN de esta, para utilizar su maquinaria metabólica y producir copias de sí mismos que saldrán de la célula para infectar a otras. ¿Pero qué es la vida? El concepto de vida ha sido objeto de reflexión desde la Grecia clásica hasta la actualidad sin que podamos decir que haya una respuesta clara y satisfactoria. Para 


\section{artnodes}

https://artnodes.uoc.edu

Neil A. Campbell y Jane B. Reece existen una serie de propiedades que nos permiten diferenciar la vida de la no vida (Campbell y Reece, 2019: 3). Entre ellas, la capacidad de los organismos vivos de presentar un orden y una organización compleja; la homeostasis, capacidad que les permiten regular sus condiciones internas y mantenerlas en equilibrio; la existencia de un patrón específico de crecimiento y desarrollo para cada organismo determinado por la pertenencia a su especie. Además, un ser vivo es capaz de utilizar la energía externa, incorporarla a su organismo y transformarla para mantener las funciones vitales por medio del metabolismo. Otras características serían la capacidad de responder al ambiente y a los estímulos que los rodean, y la capacidad de reproducirse y evolucionar. Todas ellas nos permitirían determinar qué es la vida. Sin embargo, es fácil cuestionar este conjunto de particularidades como específicas de los organismos vivos. Algunas de ellas las cumplen también entes que consideramos habitualmente como no vivos, mientras que otros que consideramos como vivos no cumplen todas en todas las fases de su vida. Algunos ejemplos de esto los señala Jabr en Why life does not really exist (Jabr, 2013). Así, la capacidad de autoorganización la podemos encontrar también en el crecimiento de los cristales. Según García-Ruiz, Melero y Hyde (García-Ruiz, Melero-García y Hyde, 2009), ciertos materiales cristalinos de sílice se generan por autoensamblaje de cristales nanométricos, adoptando formas biológicas similares a las de las conchas de los moluscos y otros seres vivos. Otro ejemplo paradigmático para Jabr que cumple la característica de utilización de la energía es el fuego, el cual consumiría energía para hacerse de mayor tamaño y, sin embargo, no lo consideramos como un ser vivo. Por otro lado, muchos organismos permanecen en largos periodos de latencia hasta que se vuelven a reunir las condiciones necesarias para tornar «a la vida». En este sentido cabe preguntarse: ¿una semilla es un ser vivo o no vivo? Algunas especies de medusas, por ejemplo: la mediterránea Turritopsis dohrnii es citada con frecuencia por ser conocida como «medusa inmortal», pues tiene la capacidad de alternarse entre su estado de pólipo y su estado adulto de larva, volviendo al primero en condiciones de estrés ambiental que supongan un peligro para su supervivencia. El mismo organismo, cambiando de estado y sin necesidad de reproducirse, viviría eternamente.

En analogía con las características que definen la vida, se han creado algoritmos con capacidad de evolución y adaptación al medio, máquinas y bots capaces de autorreparación o de crear nuevas máquinas similares (reproducción) e intercambiar información (Fogel, 2006).

Para Jabr el intento de definir la vida parte de un error categorial: la vida como tal es un concepto convencional para establecer una diferencia entre lo que grosso modo consideramos como lo vivo y lo que no. La línea que separa lo vivo de lo no vivo sería una construcción teórica, no una realidad. A nivel atómico, los seres vivos y no vivos y el universo serían un conjunto de ensamblajes y desensamblajes temporales de átomos (Jabr, 2013).

Más allá de una separación estricta entre lo vivo y lo no vivo, superar este dualismo desde una comprensión gradual de los estados
Entre lo vivo y lo no vivo. Edadismo, capacitismo, LGTBIQ*fobia y artivismo antirracista en el Estado español durante los primeros meses de la COVID-19

de la materia nos será útil a la hora de repensar los fenómenos implicados en un proceso complejo como la pandemia de la COVID-19.

Vayamos al caso que nos ocupa.

\section{El virus como amenaza de China: mercado, edadismo, capacitismo, especismo, transespecismo y racismo}

EI SARS-CoV-2 surge como una amenaza con terribles consecuencias para la salud pública y la economía global. Este virus zombi, entre lo vivo y no vivo, como una figura más que puebla la literatura y la producción visual en forma de imaginario apocalíptico, se presenta en las películas y series de zombis de las plataformas de entretenimiento (Netflix, HBO), como la surcoreana Kingdom (2019), conviviendo con películas sobre pandemias víricas que amenazan con ser el fin de la especie humana en el antropoceno: Contagion (2011).

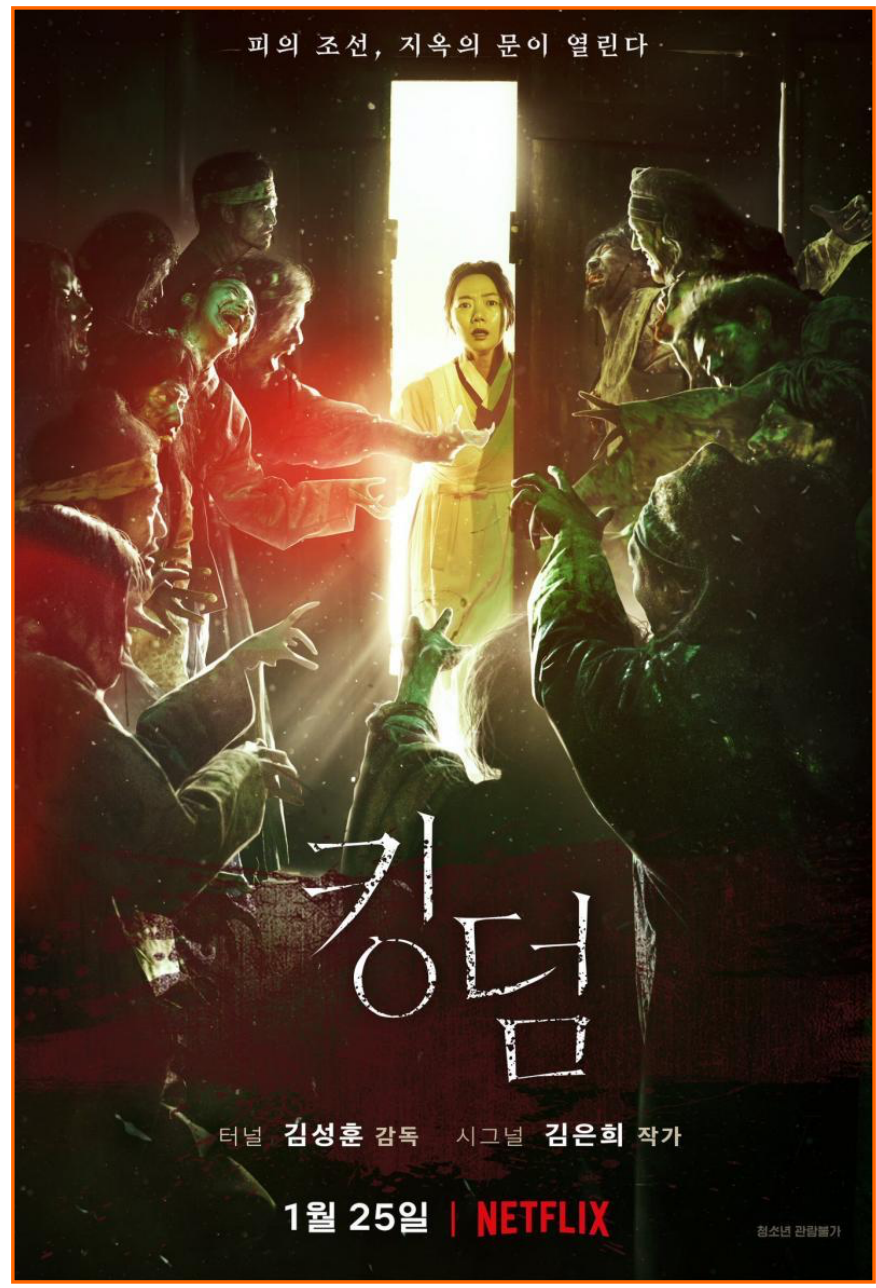

Figura 1. Kim Seong-hoon, Park In-je. Cartel promocional de "Kingdom". 2019. https://www. netflix.com/title/80180171 


\section{artnodes}

https://artnodes.uoc.edu

El virus será el monstruo que amenaza la futurabilidad de la especie, un virus queer, en la medida en que lo queer amenaza la reproductibilidad heterosexual como sentido último del humano cishetero (Edelman, 2014).

EI SARS-CoV-2, como actante, evidencia y refuerza las desigualdades y violencias estructurales ya presentes en la sociedad, tales como el edadismo, el capacitismo, el especismo, el racismo o la LGTBIQ*fobia. En este sentido, Latour señaló en el caso del virus SARS de 2002 cómo «el contagio redefine los mapas sociales» (Latour, 2008: 157), interviniendo en la creación de nuevas reconfiguraciones de los grupos humanos y sus dinámicas de poder.

Durante el confinamiento en 2020 , las redes sociales y las televisiones públicas y privadas presentaron un imaginario de inspiración mítica de la pandemia en el que las calles vacías de humanos remitían tanto a un infierno posapocalíptico como a un Edén perdido primigenio y recuperado por la naturaleza. Así, la idea del humano como amenaza para la supervivencia del planeta que se ha consolidado desde los debates en torno al antropoceno se ilustra con imágenes de un supuesto avance de la naturaleza y un repliegue de la contaminación.

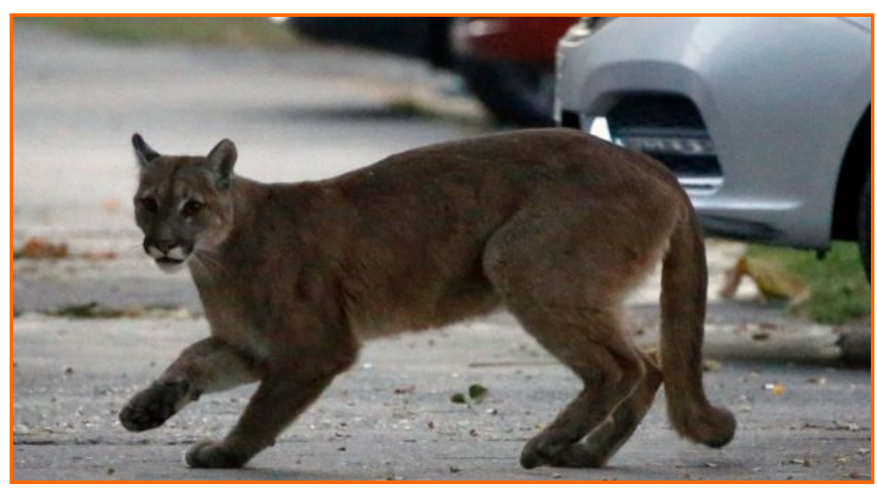

Figura 2. Puma en Santiago de Chile. 2020. https://www.bbc.com/mundo/noticias-52216020

La crisis desencadenada evidenció el sistema de valores del tardocapitalismo. Por ejemplo, en el caso del edadismo, se crea una brecha social intergeneracional que responsabiliza a los jóvenes de los rebrotes ocurridos y relegó a la falta de atención médica y a una muerte segura durante la primera ola a los ancianos, bajo criterios de prioridades establecidas en lógicas de conflicto bélico basadas en probabilidades de supervivencia. El edadismo supone la pérdida de la generación de nuestros mayores, la crisis de la COVID visibilizó cómo están adscritos a una categoría de no-humanos en tanto que sujetos no productivos, carga para el sistema y prescindibles. El periódico EI
Entre lo vivo y lo no vivo. Edadismo, capacitismo, LGTBIQ*fobia y artivismo antirracista en el Estado español durante los primeros meses de la COVID-19

Mundo publicó una noticia con el titular: «Las muertes por COVID-19 provocan la primera caída en la nómina de las pensiones» (Viaña y Urrutia, 2020).

Al paralizarse el sistema económico global mediante la inmovilidad de los cuerpos en confinamiento, el virus se manifiesta como un agente «incapacitante». Esta idea de la supresión de la movilidad de los cuerpos se enmarca dentro de una visión capacitista global, según la cual, las personas con diversidad funcional son incapacitadas, no productivas y, por tanto, también prescindibles.

Por otro lado, se desencadenan los fantasmas del racismo que afectan inicialmente a la población migrante asiática y, con posterioridad, a los temporeros, que serán vistos como fuente de infección (EFE, 2020b).

Las comunidades que sufren situaciones de discriminación son especialmente víctimas de la pandemia, que ha visibilizado las desigualdades; la población LGTBIQ*, migrante, racializada, sin hogar y pobre verán acrecentadas sus situaciones de precariedad y violencia (Fonseca, Muniz y Pina, 2020). En este contexto se desatan las protestas globales del movimiento Black Lives Matter tras la muerte de George Floyd.

Como en el caso de la sífilis, llamada morbo gálico o mal francés (lommi, 2010) o la llamada gripe española, la detección de los primeros casos en Wuhan, China, asocia la COVID-19 con este país y las costumbres alimenticias y culturales de sus ciudadanos, donde una supuesta tradición de consumo de animales salvajes se presenta como una costumbre generalizada causante de la aparición de la enfermedad. Estas presuntas diferencias culturales «bárbaras» fueron utilizadas como fuente de argumentos racistas. Las formas de cocinar, los olores de las comidas, los alimentos y las especias se usarán para señalar y reconocer al otro como ajeno y extraño al «nosotros». Varios artículos abordan esta cuestión: «"¿Cómo no van a contraer virus si los chinos comen gatos, perros, murciélagos, culebras y ciempiés?", se preguntan algunos. Las redes sociales hierven estos días con fotos de ciudadanos chinos con mascarilla, pero también devorando ranas crudas, tomando sopa de murciélago 0 degustando ratas. [...] Es cierto que, en determinadas ocasiones, los chinos consumen animales exóticos, pero ni se trata de una práctica generalizada ni la Organización Mundial de la Salud (OMS) ha confirmado que ese sea el foco de la infección» (Centenero y Rodríguez, 2020).

La pandemia, posiblemente originada por transmisión transespecífica $^{1}$ (zoonosis) del coronavirus desde animales salvajes a animales humanos, es percibida como un castigo consecuencia de la transgresión de un tabú originario (similar en el ámbito de la identidad a la transespeciefobia que sufren las personas transespecie ${ }^{2}$ que se identifican en parte como no-humanas): el tabú de atravesar las fronteras entre especies que separan los

1. Un virus es transespecífico cuando ha saltado entre distintas especies. En el caso del SARS-CoV-2 habría pasado de un animal no humano a un animal humano en un momento reciente de su ciclo evolutivo.

2. Las personas transespecie se identifican total o parcialmente con seres no humanos, ya sean estos animales o seres míticos. En las dos últimas décadas han crecido en número y visibilidad, especialmente en redes sociales y foros específicos. Esta identificación les lleva a encarnar a estas otras entidades mediante la performatividad y gestualidad mimética o la transformación corporal por medio de prótesis e implantes. 


\section{artnodes}

https://artnodes.uoc.edu

humanos de los animales. En el caso del consumo de perros y gatos, estas fronteras son las mismas que establecen la prohibición del canibalismo: el animal de compañía es percibido como un miembro más de la familia y, por tanto, humanizado. Su consumo se representa como una suerte de antropofagia. Por otro lado, ciertos «animales salvajes», término genérico que engloba la diversidad de animales no domésticos como el murciélago, son representados como una posible fuente portadora del virus y, por tanto, del mal. El consumo de su carne como cuerpo 0tro, supondría abrir las puertas en humanos a la entrada de este mal. Profanar estos tabúes tendrá como consecuencia una plaga, idea que remite al castigo divino de las diez plagas de Egipto en el libro del Éxodo del Antiguo Testamento. Esta permeabilización del yo y su disolución en otras entidades no-humanas en el discurso inmunitario habían sido señaladas por Haraway:

«La inmunidad puede asimismo ser concebida en términos de especificidades compartidas: del yo semipermeable capaz de relacionarse con otros (humanos y no-humanos, internos y externos), pero siempre con consecuencias finitas; de posibilidades e imposibilidades situadas de individuación e identificación; y de fusiones parciales y peligros» (Haraway, 1995: 388).

En el mercado, los efectos de la propagación del coronavirus se producen en el contexto del conflicto comercial chino-estadounidense iniciado en marzo de 2018 con la aplicación de aranceles por parte del Gobierno americano a los productos de origen chino y se manifiestan, de manera paralela, en el cuerpo de los individuos afectados y en lo que podríamos llamar el cuerpo del mercado, en la medida en que se van viendo afectados en su estado de buena salud.

El virus sirve así de metáfora de la gran amenaza China. En una entrevista del 3 de agosto de 2019, el economista János Kornai dice: «China no se conforma con ser una de las principales potencias, está tratando de dominar el mundo» (Orgaz, 2019).

Los centros financieros infectados tanto a nivel local como global se representan en mapas que funcionan en el imaginario mediático metafóricamente como metástasis con un foco de expansión inicial desde la ciudad de Wuhan, un importante centro financiero y nodo de transportes de la provincia China de Hubei con el resto del país.

La idea del mercado como cuerpo se evidencia en representaciones como el mapa publicado por el diario El País, en el que se muestra la evolución en los primeros momentos de expansión de la pandemia con fecha de 1 de febrero de 2020 (Andrino, Grasso y Llaneras, 2020). El mapa muestra una distribución de los brotes en una superficie del planeta cubierto de erupciones, «ronchas» rojas 0 lesiones en la piel del mercado. El virus como organismo zombi produce un cambio en el metabolismo del mercado, parasitando sus sistemas de replicación y ocasionando «problemas de salud» en la Bolsa (Gutiérrez, 2020). Paralelamente, el ecosistema financiero se ve alterado, produciéndose un reequilibrio en el que ciertas empresas, corporaciones y países se verán beneficiados.
Entre lo vivo y lo no vivo. Edadismo, capacitismo, LGTBIQ*fobia y artivismo antirracista en el Estado español durante los primeros meses de la COVID-19

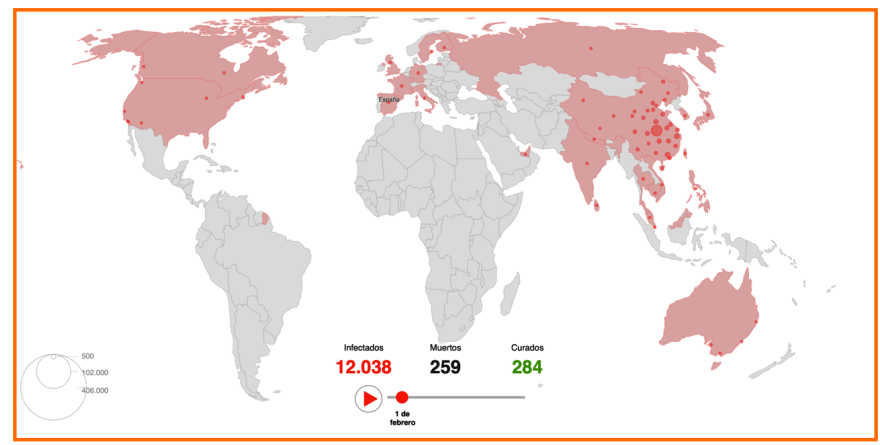

Figura 3. "El mapa del coronavirus: así crecen los casos día a día y país por país 01 de febrero". Fecha de consulta 13/04/2020 https://elpais.com/sociedad/2020/04/13/actualidad/1586788600_290634.html

Por ejemplo, la biofarmacéutica francesa Novacyt será una de las principales beneficiadas durante las primeras semanas de la crisis al poner en el mercado un test que permitía detectar la infección (Expansión, 2020). La relación entre virus y guerra económica nos permite entender este proceso más amplio que acontece en un ente abstracto e inmaterial, pero a la vez profundamente material, como son el mercado y las políticas económicas, desde la perspectiva de un fenómeno vivo, en la medida en que comparte con los seres vivos algunas características de entre las citadas anteriormente, tales como la capacidad de reproducción o, por ejemplo, la manera en que el cuerpo financiero afectado por la expansión del virus experimenta cambios en el metabolismo de la energía. En este sentido, un mercado afectado especialmente por la crisis sanitaria fue el del petróleo, dado que China es el mayor importador de petróleo a escala global. La pandemia afectó a las celebraciones de la fiesta del Año Nuevo chino, reduciéndose el consumo de energía por el cierre de centros de trabajo, industrias, oficinas, escuelas y tiendas, y la caída del precio del barril. El mercado infectado por el coronavirus se comporta como un organismo vivo reduciendo el uso de energía externa para el mantenimiento del sistema. El equilibrio homeostático se desplaza. El sistema coronavirus-mercado evolucionó paralelamente a los individuos infectados y a su expansión global.

Hasta aquí hemos visto las complejas dinámicas que se establecen en este reciente ensamblado social formado por el virus, el mercado, los medios de comunicación y el importante papel que estos actantes considerados como no vivos desempeñan en la exacerbación de las desigualdades sociales ya existentes. Veamos ahora cómo se ha producido una respuesta desde el artivismo antirracista de la comunidad de origen asiático.

\section{Artivismo antirracista de la comunidad de origen asiático en España durante la COVID-19}

Como consecuencia de este agenciamiento de industria, mercado, seres vivos/no vivos, energía, animales salvajes, humanos/ 


\section{artnodes}

https://artnodes.uoc.edu

no-humanos, virus, alimentos, procesos metabólicos, relaciones interespecie, petróleo, mascarillas, saliva, tos, prácticas culturales y gastronómicas, se desencadena un brote de racismo que evoluciona de manera infecciosa, propagándose a través de memes en las redes sociales, paralelamente al avance de la pandemia (Ma y McLaughlin, 2020).

En España y otros países occidentales, la economía, en muchos casos de subsistencia, de los ciudadanos chinos migrantes se verá afectada ya en febrero, con anterioridad al colapso global, como consecuencia de un descenso del consumo de productos de origen chino y de una bajada en la afluencia a locales regentados por esta comunidad (Hernández, 2020).

La respuesta de la comunidad asiática va desde la autoexclusión en cuarentenas voluntarias (Telemadrid, 2020) hasta la denuncia del racismo por parte de los colectivos racializados.

En febrero de 2020 cinco estudiantes de origen chino denuncian que se les impide la entrada en un local en Huelva (EFE, 2020), argumentando que eran menores de edad, y deciden comenzar una campaña de respuesta bajo el lema \#Nosoyunvirus («No soy un virus»), consistente en distribuir memes en los que se autorretratan sujetando un cartel con este eslogan (Chen, 2020).

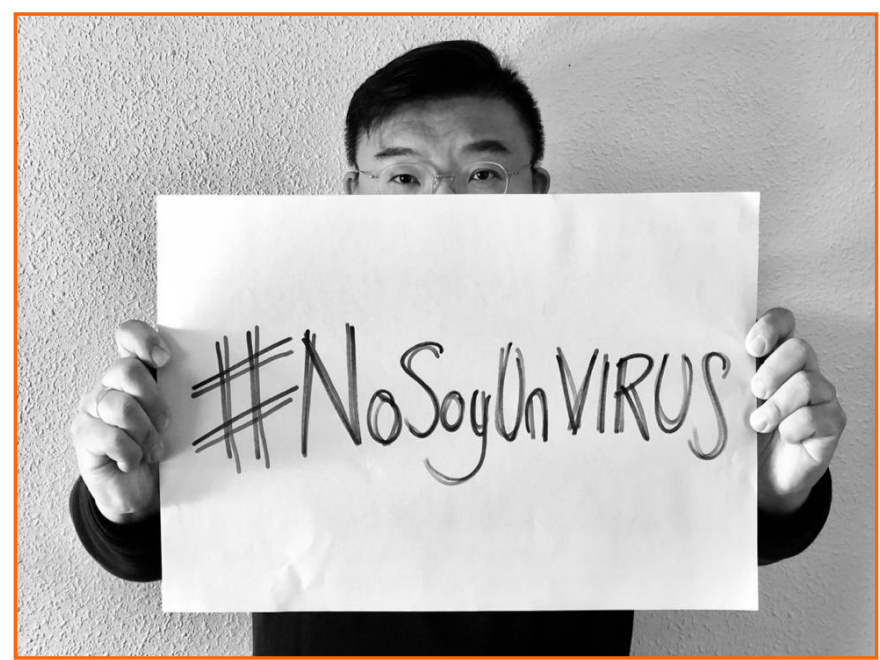

Figura 4. Antonio Liu Yang. 2 de febrero 2020. https://twitter.com/antonioliuyang/ status $/ 1223952470247923716 ? \mathrm{~s}=20$

Chenta Tsai (Taiwán, 1991), artista multimedia, activista y artivista, cantante y compositor, también conocido como Putochinomaricón, protagoniza una acción performativa con un carácter reivindicativo de denuncia y visibilización del racismo contra la comunidad asiática en estas semanas previas a la primera oleada pandémica. Durante la Semana de la Moda en Madrid, Madrid Fashion Week, en plena escalada del agenciamiento vírico, Chenta Tsai desfila como modelo de Coconutscankill con el lema «No soy un virus» escrito en el pecho.
Entre lo vivo y lo no vivo. Edadismo, capacitismo, LGTBIQ*fobia y artivismo antirracista en el Estado español durante los primeros meses de la COVID-19

Tanto la campaña \#Nosoyunvirus como la imagen de Chenta Tsai en el desfile se harán «virales».

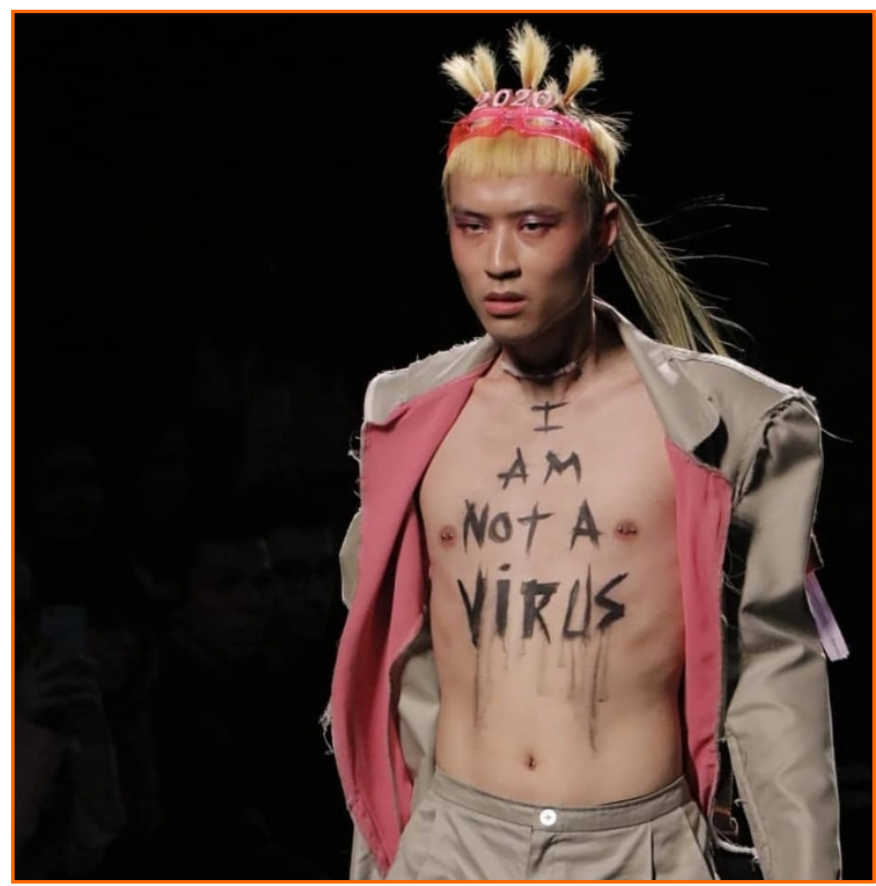

Figura 5 “I am not a virus”. Instagram foto. @putochinomaricon 2 de febrero 2020. https://www. instagram.com/p/B8EmxsNoQJs/?utm_source=ig_web_copy_link

« am not a virus».

«Hoy @amaracaruncho me invitó a desfilar para @coconutscankill en Madrid Fashion Week».

«El debate en torno al virus está teniendo connotaciones raciales que afectan a la comunidad racializada asiática y quise aprovechar esta ocasión para mandar todo mi apoyo a aquelles hermanes que sufren racismo debido a ello» (@putochinomaricon, 2 de febrero, 2020).

Las primeras generaciones de españoles descendientes de asiáticos comienzan a alcanzar la mayoría de edad en la primera década del 2000. Chenta Tsai, criado en el barrio madrileño de Vallecas, formará parte de un creciente número de artistas y activistas que toman conciencia de la situación económica, política y social de exclusión de sus comunidades de origen. De manera interseccional, Chenta Tsai parte de una posición identitaria atravesada por la raza, la clase, el género y la orientación sexual, denunciando, desde una posición queer, el racismo y la plumofobia de la comunidad gay homonormativa.

Los colectivos racializados con un marcado carácter identitario señalarán la importancia de la racialización como eje fundamental de la discriminación institucional a los migrantes. La denuncia se extenderá no solo al racismo institucional, sino también al de la izquierda blanca tradicional española, incluyendo colectivos históricos antirracistas cuya organización y dirección era fundamentalmente blanca. La blanquitud como herramienta de opresión será fundamental en la crítica de estos 


\section{artnodes}

https://artnodes.uoc.edu

nuevos colectivos en los que las prácticas activistas y artivistas confluyen en un llamamiento a un sujeto político racializado.

En este mismo contexto de denuncia, Quan Zhou Wu, ilustradora y diseñadora nacida en Algeciras en 1989 y creadora de las novelas gráficas Gazpacho agridulce y Andaluchinas por el mundo, protagonizará una acción delante del Ministerio de Asuntos Exteriores en la que se fotografía con un cartel en el que se lee: «No tengo el coronavirus» y que difunde en las redes sociales (@gazpachoagridulce, 2 de febrero, 2020).

Los cómics, en palabras de la autora, le servirán como herramienta para construir historias que revelan el racismo interiorizado (Díaz, 2020).

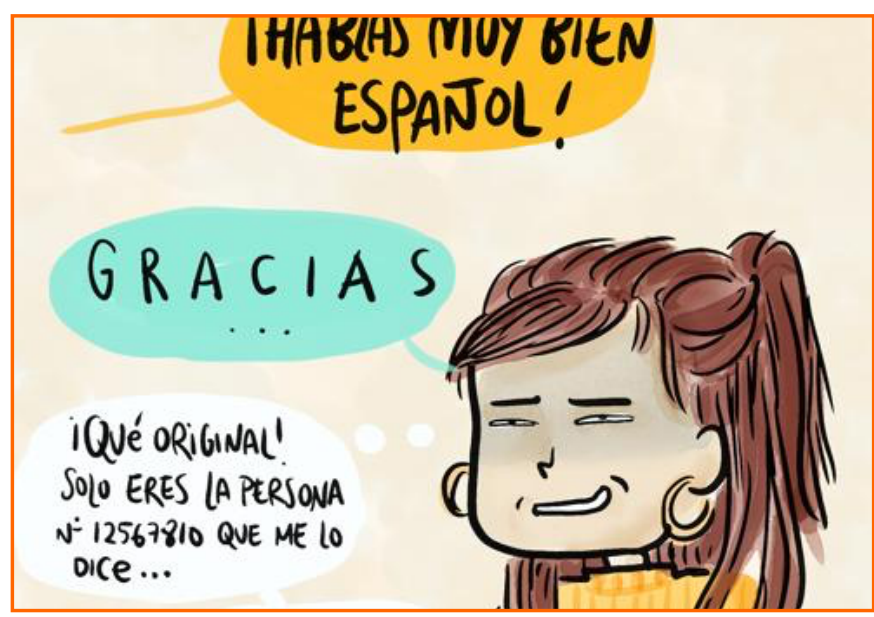

Figura 6. Quan Zhou Wu. "Hablas muy bien español”. 2020

Estas acciones no solo visibilizaron el racismo creciente contra la comunidad asiática, sino que funcionaron como un primer mecanismo de denuncia y concienciación ante las consecuencias políticas y sociales desencadenadas por la pandemia.

\section{LGTBIQ*fobia vírica}

En este sentido, la pandemia afectará también de manera especial a la comunidad LGTBIQ*. El confinamiento y la saturación de los hospitales dificultarán el acceso a las terapias hormonales de las personas trans.

La FELGTB (Federación Estatal de Lesbianas, Gais, Transexuales y Bisexuales) denunció cómo el confinamiento agravó las situaciones de discriminación sufridas por las personas LGTBIQ*, incrementándose las situaciones de violencia doméstica, especialmente contra aquellos jóvenes que habían salido recientemente del armario en el entorno familiar (Europa Press, 2020).

A nivel global se denunció la dificultad para acceder a los tratamientos retrovirales para las personas seropositivas debido a las
Entre lo vivo y lo no vivo. Edadismo, capacitismo, LGTBIQ^fobia y artivismo antirracista en el Estado español durante los primeros meses de la COVID-19

situaciones de colapso. En el caso de las personas LGTBIQ* refugiadas o migrantes, que han huido de sus respectivos lugares de origen por persecución LGTBIQ*fóbica, no cuentan con las mismas redes de apoyo que tienen sus compatriotas cishetero, no pudiendo acudir a su propia comunidad a solicitar ayuda.

Las personas LGTBIQ* ancianas, que viven con frecuencia en soledad 0 en residencias donde han tenido que volver al armario para no sufrir el acoso de sus compañeros, carecen con frecuencia de familiares que les apoyen en esos momentos.

De manera habitual se ha relacionado en los medios la COVID-19 con un episodio reciente de agenciamiento vírico en la historia contemporánea. Se trata de la pandemia ocasionada por el VIH, virus causante del Síndrome de Inmunodeficiencia Adquirida (sida).

Uno de los errores más comunes cometidos ha sido establecer comparaciones que simplifican problemáticas diferenciadas. EI SARSCov-2 y el VIH no son comparables ni en la cuestión biológica de la enfermedad ni en el estigma y las consecuencias de discriminación que tuvo y tiene.

Podemos ver un intento, en este caso torpe, de vincular la COVID-19 con la población LGTBIQ*, en la noticia recogida por The Advocate el 29 de enero del 2020 en el que se citan las declaraciones de Rick Wiles, un predicador fundamentalista cristiano acreditado por la Administración Trump como reportero de prensa en la visita del presidente norteamericano a Suiza.

Rick Wiles declaró que «Dios había enviado el coronavirus para destruir a la gente LGBTI» (Ring, 2020).

Una relectura desde esta concepción de la importancia de la diversidad de actantes humanos y no humanos implicados en la lucha llevada a cabo por los colectivos activistas y artivistas contra el sida de los noventa, La Radical Gai y LSD, nos ayuda a comprender las complejas dinámicas y fuerzas que intervinieron en el ensamblaje en el que participaron no solo las personas seropositivas, los familiares, las aliadas, tanto individual como colectivamente, o los políticos, sino también la institución médica, Lavapiés, las jeringuillas, los condones, las cenizas de los muertos, el queercore, los linfocitos, el AZT, Ios antibióticos, la sangre, las infecciones oportunistas, los afectos, el miedo, la rabia, las drogas sintéticas, los discursos de los representantes de la Iglesia, las transfusiones, las discotecas y los cuartos oscuros como espacios de relación, la noche y el propio $\mathrm{VIH}$, y que se refleja en la producción artística, así como en una serie de fanzines y fotografías que documentaron sus acciones públicas.

En el caso de la COVID-19, los botellones protagonizados por jóvenes serán señalados como máximos responsables de los rebrotes. Todo esto nos permite pensar en los distintos grados y formas de participación de los actantes en el discurso con el que se construye este ensamblaje. Desde una lectura horizontal de la participación de todos estos agentes, el ser humano no ocuparía necesariamente una posición central, sino que la agencia se distribuiría en mayor 0 


\section{artnodes}

https://artnodes.uoc.edu

menor grado entre los participantes, de una forma más rizomática, empleando la metáfora del mosaico de la TAR ${ }^{3}$.

Sin embargo, no podemos perder de vista que una crítica a las teorías que hacen hincapié en la importancia de la agencia de los no-humanos en los fenómenos sociales es que pueden conducir a una cierta desresponsabilización de los agentes humanos implicados en las consecuencias de algo tan complejo como fue la crisis del sida y, en este caso, de la COVID-19.

\section{Conclusiones}

Este estudio ha hecho un análisis del agenciamiento vírico de la COVID en los primeros meses de formación de los nuevos ensamblajes sociales desde una perspectiva interseccional, empleando herramientas como las facilitadas por la TAR, evitando caer en simplificaciones que inclinen la balanza hacia el rol que desempeñan los actantes no humanos en los procesos de construcción de estos ensamblaje complejos o que reduzcan la relevancia de los

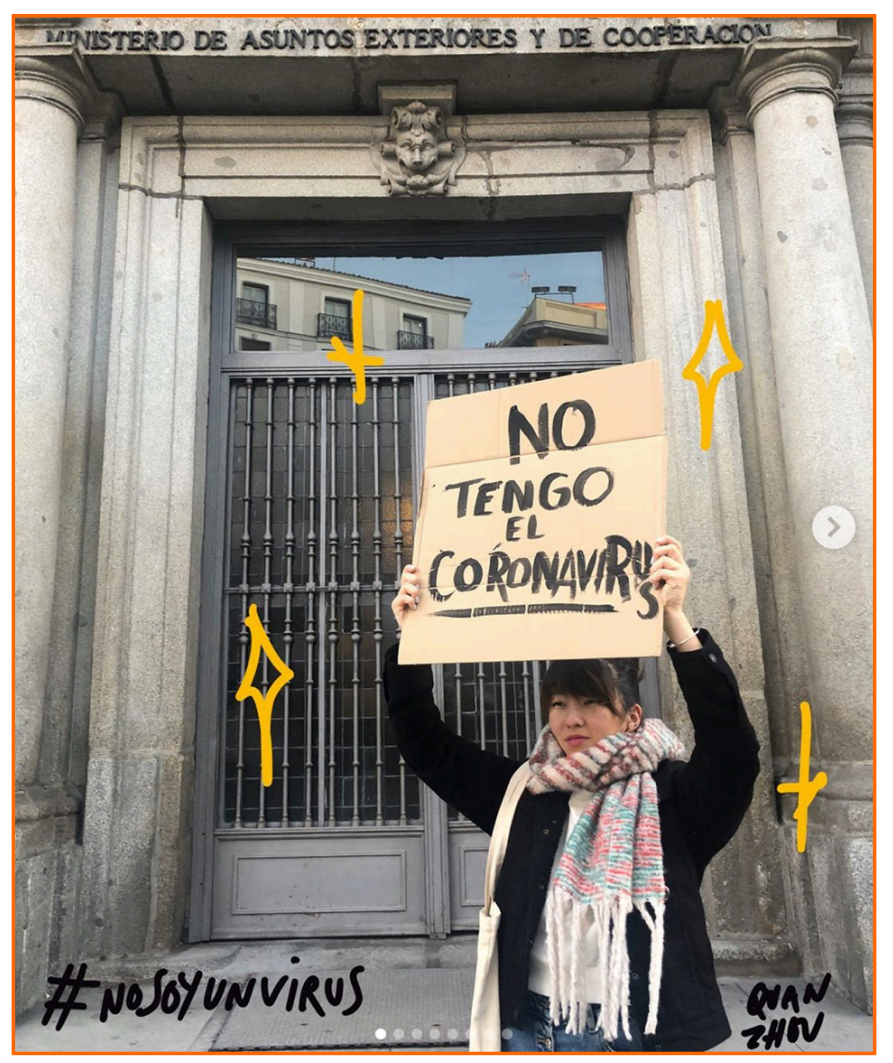

Figura 7: Quan Zhou. "No tengo el coronavirus". 2 de febrero 2020. https://www.instagram. com/p/B8EEVIBISrk/
Entre lo vivo y lo no vivo. Edadismo, capacitismo, LGTBIQ^fobia y artivismo antirracista en el Estado español durante los primeros meses de la COVID-19

factores humanos y sus instituciones culturales, sin renunciar a la importancia de los factores multicausales humanos y no humanos, más allá de la dicotomía convencional de lo vivo y lo no vivo y sus difusas fronteras, para ayudarnos a comprender una situación política, personal y global como la de la crisis actual desencadenada por la pandemia. Las representaciones artísticas producidas en estos agenciamientos por artistas y artivistas no solo actúan como mecanismo de contestación a los procesos crecientes de exclusión social, racismo y LGTBIQ^fobia a nivel micro y macropolítico en situaciones crecientes de precariedad y discriminación, sino que también visibilizan a comunidades y problemáticas excluidas de la esfera pública.

\section{Referencias bibliográficas}

Andrino, Borja, Daniele Grasso, y Kiko Llaneras. 2020. «El mapa del coronavirus: así crecen los casos día a día y país por país». El País, 13 abril, 2020. https://elpais.com/sociedad/2020/04/13/ actualidad/1586788600_290634.html.

Campbell, Neil B., y Jane B. Reece. 2001. Biología: Conceptos y relaciones. Buenos Aires: Médica Panamericana.

Centenero, Jesús, Sara Rodríguez. 2020. «¿Los chinos sufren el coronavirus por comer animales exóticos?». Agencia EFE, 7 febrero, 2020. https://www.efe.com/efe/espana/efeverifica/ los-chinos-sufren-el-coronavirus-por-comer-animales-exoticos/50001435-4168310.

Chen, Paloma. 2020. «La comunidad china se organiza: de la campaña \#Nosoyunvirus a la aventura política». El Salto Diario, 14 febrero, 2020. https://www.elsaltodiario.com/racismo/comunidad-chinaorganiza-campana-no-soy-virus-aventura-politica.

Díaz Guardiola, Javier. 2020. «Quan Zhou Wu: "El cómic sirve como herramienta para descubrir el racismo que llevamos interiorizado"». ABC, 22 septiembre, 2019. https://www.abc.es/cultura/cultural/ abci-quan-zhou-comic-sirve-como-herramienta-para-descubrirracismo-Ilevamos-interiorizado-201909220049_noticia.html.

Edelman, Lee. 2014. No al futuro: La teoría queer y la pulsión de muerte. Madrid: Egales.

EFE. 2020. «Cinco estudiantes denuncian no pudieron entrar en bar de Huelva por ser chinos». $A B C, 1$ febrero, 2020. https://www. abc.es/sociedad/abci-cinco-estudiantes-denuncian-no-pudieronentrar-huelva-chinos-202002011556_noticia.html.

EFE. 2020. «Los alojamientos de temporeros extranjeros, un riesgo añadido de coronavirus». El Mundo, 25 julio, 2020. https://www. elmundo.es/ciencia-y-salud/salud/2020/07/25/5f1bf0fafc6c83 b4228b469b.html.

3. TAR (Teoría del Actor Red). 


\section{artnodes}

https://artnodes.uoc.edu

Europa Press. 2020. «FELGTB y entidades internacionales denuncian que el confinamiento 'agrava las discriminaciones' al colectivo». Europa Press. 14 mayo, 2020. https://www.europapress.es/sociedad/noticia-felgtb-entidades-internacionales-denuncian-confinamiento-agrava-discriminaciones-colectivo-20200514133957. html.

Expansión. 2020. «El coronavirus pone en órbita en Bolsa a Novacyt». Expansión, 10 febrero, 2020. https://www.expansion.com/merca dos/2020/02/10/5e412354e5fdeaa3148b45a9.html.

Fogel, David B. 2006. Evolutionary Computation: Toward a New PhiIosophy of Machine Intelligence. New York: IEEE Press, NY. DOI. https://doi.org/10.1002/0471749214

Fonseca, Bruno, Bianca Muniz, y Rute Pina. 2020. «Pandemia, pobreza y racismo: el número de personas negras fallecidas en Brasil aumentan a mayor ritmo». El Diario, 23 mayo, 2020. https://www. eldiario.es/internacional/semanas-numero-negros-coronavirusbrasil_1_5972602.html.

García-Ruiz J., Emilio Melero-García, y Stephen T. Hyde. 2009. «Morphogenesis of Self-Assembled Nanocrystalline Materials of Barium Carbonate and Silica». Science 323, Issue 5912: 362-365. DOI: https://doi.org/10.1126/science. 1165349

Gunderman, Richard. 2018. «Diez mitos que aún creemos sobre la 'gripe española' de 1918». El País, 21 enero, 2018. https://elpais. com/elpais/2018/01/16/ciencia/1516096077_476907.html

Gutiérrez, Hugo. 2020. «Las Bolsas sufren más con el coronavirus que tras la caída de Lehman Brothers». El País, 22 marzo, 2020. https://elpais.com/economia/2020-03-22/las-bolsas-sufrenmas-con-el-coronavirus-que-cuando-cayo-lehman-brothers. html.

Iommi Echeverría, Virginia. 2010. «Girolamo Fracastoro y la invención de la sífilis». Historia, Ciencias, Saúde-Manguinhos 17(4): $877-$ 884. D0I: https://doi.org/10.1590/S0104-59702010000400002

Haraway, Donna. 1995. Ciencia, cyborgs y mujeres. La reinvención de la naturaleza. Madrid: Cátedra.

Hernández, J. 2020. «Los negocios chinos sufren pérdidas del $30 \%$ por la psicosis del coronavirus». Información, 6 febrero,
Entre lo vivo y lo no vivo. Edadismo, capacitismo, LGTBIQ*fobia y artivismo antirracista en el Estado español durante los primeros meses de la COVID-19

2020. https://www.diarioinformacion.com/alicante/2020/02/06/ negocios-chinos-sufren-perdidas-30/2231703.html.

Jabr, Ferris. 2013. «Why Life Does Not Really Exist». Scientific American, 2 diciembre, 2013. https://blogs.scientificamerican.com/ brainwaves/why-life-does-not-really-exist/

Latour, Bruno. 2008. Reensamblando los social: una introducción a la Teoría del Actor Red. Buenos Aires: Ediciones Manantial.

Ma, Alexandra, y Kelly McLaughlin. 2020. «The coronavirus is causing increased reports of racism and xenophobia against Asian people at college, work, and supermarkets». Business Insider, 3 febrero, 2020. https://www.businessinsider.com/wuhan-coronavirusracism-asians-experience-fears-outbreak-2020-1? IR=T.

Orgaz, Cristina J. 2019. "China no se conforma con ser una de las principales potencias, está tratando de dominar el mundo: entrevista con el economista János Kornai». BBC News Mundo, 3 agosto, 2019. https://www.bbc.com/mundo/noticias-internacional-49206327.

Ring, Trudy. 2020. «God Sent Coronavirus to Destroy LGBTQ People, Says Trump-OK'd Preache». The Advocate, 29 enero, 2020. https:// www.advocate.com/religion/2020/1/29/god-sent-coronavirusdestroy-lgbtq-people-says-trump-okd-preacher.

Telemadrid. 2020. «Cuarentena voluntaria en los comercios chinos de Usera». Telemadrid, 7 febrero, 2020. http://www.telemadrid. es/programas/120-minutos/Cuarentena-voluntaria-comercioschinos-Usera-2-2202399758--20200207020504.html.

Tsai, Chenta (@putochinomaricon). 2020. «l am not a virus». Instagram photo, 2 febrero, 2020. https://www.instagram.com/p/ B8EmxsNoQJs/?utm_source=ig_web_copy_link.

Viaña, Daniel, César Urrutia. 2020. «Las muertes por Covid-19 provocan la primera caída en la nómina de las pensiones». El Mundo, 26 mayo, 2020. https://www.elmundo.es/economia/macroecon omia/2020/05/26/5eccd095fc6c839e0c8b4620.html.

Zibechi, Raul. 2020. «A las puertas de un nuevo orden mundial». En Sopa de Wuhan, editado por Pablo Amadeo, 113-118. ASPO.

Zhou Wu, Quan. 2020. «Coronavirus o xenofobovirus». Instagram photo, 2 febrero, 2020. https://www.instagram.com/p/B8EEVIBISrk/. 


\section{artnodes}

https://artnodes.uoc.edu

\section{CV}

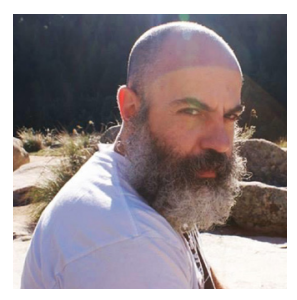

\section{Andrés Senra}

Universitat Oberta de Catalunya (UOC). Grado de Artes.

asenrab@uoc.edu

Graduado en Filosofía por la UNED (2018), licenciado en Ciencias Biológicas por la Universidad Complutense de Madrid (1993) y candidato a doctor por la Universidad de Salamanca, programa de Filosofía. Es profesor colaborador del Grado de Artes en la Universitat Oberta de Catalunya (UOC), investigador y artista. En sus trabajos de investigación artística recientes ha abordado cuestiones como las utopías queer, los nuevos materialismos y neovitalismos, el monstruo, las performatividades animal-humano, las estéticas de la extinción, el archivo como obra de arte o la historia política y afectiva de la comunidad LGTBIQ* madrileña, trabajo por el que obtuvo una beca de investigación en el Museo Nacional Centro de Arte Reina Sofía (MNCARS) con el proyecto Archivo queer?, 2013.

Ha recibido entre otros los siguientes premios y becas: Ayudas para la investigación, producción y creación artística Ministerio de Cultura y Deporte, 2020; Ayudas a la Creación en Artes Visuales Comunidad de Madrid, 2017; Ayudas Fundación BBVA a la Creación en Videoarte, 2015; Beca MAEC-AECID «Programa ART-EX», 2014; Participar.de, Goethe Institut e Instituto Cervantes, 2012. 